\title{
SURVEILLANCE OF ANTI-TUBERCULAR DRUG RESISTANCE
}

\author{
G.C. $G^{1}$, Rijal $B^{2}$, Sharma A $P^{1}$
}

\section{ABSTRACT}

Tuberculosis is the leading cause of death in Nepal. Failure in early detection and drug resistance are two most important problems in treatment and cure of the tuberculosis. The objective of the study was to assess the drug resistance pattern in Mycobacterium tuberculosis isolated in Tribhuvan University teaching Hospital. More than $85 \%$ of isolates were sensitive to all the four drugs and $5.5 \%$ of isolates were multidrug resistant. The drug resistant isolates were obtained more frequently from previously treated patients. More extensive studies should be carried out by independent organizations to collect more representative data on drug resistance tuberculosis.

\section{Key Words: Tuberculosis, drug resistance and surveillance.}

\section{INTRODUCTION}

Tuberculosis is a global emergency. Presently, 8 million new cases occur each year and 3 million die with tuberculosis in the world. ${ }^{1}$ Nearly $38 \%$ of the global burden of TB exists in the SAARC member countries. Three of the SAARC member countries, Bangladesh, Pakistan and India are among the 22 high burden countries in the world. Thirty seven percent of the global TB cases occur in these three countries. At present there are 80,000 tuberculoses patients including 44000 new tuberculosis cases in Nepal and 9,000cases die of tuberculosis each year. ${ }^{2}$ The prevalence of tuberculosis has been found to be high in the productive age group of the population ${ }^{3,4}$ Resistance of M.tuberculosis to antibiotics is a man made amplification of spontaneous mutations in the genes of tubercle bacilli. ${ }^{5}$ Although tuberculosis is a curable and preventable disease, unfortunately, it does not happen. The increasing number of resistant cases to anti-tuberculosis treatment in developing countries has alarmed the patients and the physician's equally. ${ }^{6}$ Drug resistance

1. Central Department of Microbiology, Kritipur, Tribhuvan University (TU), Kathmandu, Nepal.

2. Department of Microbiology, TU Teaching Hospital and Maharajgunj Campus, IOM, Kathmandu, Nepal.

Address for correspondence : Dr. Basista Rijal

Assitant Professor

TU Teaching Hospital, Maharajgunj, Kathmandu

GPO Box: 12498, Kathmandu, Nepal. 
complicates tuberculosis treatment. ${ }^{7}$ Multi drug resistance (MDR) is defined as resistance to at least isoniazid and Rifampicin, the two most potent drugs and the mainstays of anti-tuberculosis treatment. ${ }^{8}$ MDR tuberculosis (TB) is the public health threat requiring sound epidemiological data. Resistant to both Isoniazid $(\mathrm{H})$ and rifampicin ${ }^{\circledR}$, MDR TB is difficult to treat. ${ }^{9}$

The objectives of the study were to assess the level of drug resistance in isolates obtained from out patients and inpatients and help physicians to review the treatment in those patients not responding to therapy due to various reasons.

\section{MATERIALS AND METHODS}

Seventy new and 4 isolates obtained from previously treated cases were studied over a period of one year from January to December 2000 at Tribhuvan University Teaching Hospital (TUTH). Sputum samples were collected from the suspected pulmonary tuberculosis where as variety of sample according to the site such as pleural fluid, ascitic fluid, urine, etc were collected from suspected extrapulmonary tuberculosis. Those specimens were processed according to the modified Petroff Method (WHO/TB/98.258) and then inoculated in Ogawa media and incubated at $37^{\circ} \mathrm{C}$ for $6-8$ weeks. Typical cream colored buff and rough colonies against the green egg based medium were observed. Those colonies were identified by biochemicals and Niacin test. After that those culture were subjected for antitubercular drug sensitivity test.

The sensitivity test was done by the "Absolute concentration method". For the anti-tuberculosis drug sensitivity test $1 \%$ ogawa medium was used with anti-tuberculosis drugs in the following concentrations: isoniazid (1NH) $0.1 \mu \mathrm{g} / \mathrm{ml}, 1 \mu \mathrm{g} /$ $\mathrm{ml}, 5 \mu \mathrm{g} / \mathrm{ml}$, Rifampicin (RMP) $10 \mu \mathrm{g} / \mathrm{ml}, 50 \mu \mathrm{g} / \mathrm{ml}$, Streptomycin (SM) $20 \mu \mathrm{g} / \mathrm{ml}, 200 \mu \mathrm{g} / \mathrm{ml}$,
Ethambutol (EMB) $2.5 \mu \mathrm{g} / \mathrm{ml}, 5 \mu \mathrm{g} / \mathrm{ml}$. The tubes were incubated at $37^{\circ} \mathrm{c}$ for 6 weeks.

\section{RESULTS}

Of the 74 isolates tested for antimicrobial sensitivity four were from previously treated patients. During the study period four patients were documented with pervious drug exposure. All the four isolates from the previously treated patients were resistant to two or more anti tuberculosis antibiotics.

Among the 70 untreated patients, 63 (90\%) of isolates were sensitive to all four antibiotics but the remaining was resistant to two or more antibiotics. Therefore primary drug resistance (PDR) was seen in $1(1.4 \%)$ to EMB, $3(4.3 \%)$ to two drugs, $2(2.8 \%)$ to three drugs and $1(1.4 \%)$ of the isolates to four drugs as shown in Table.1. The overall proportion of PDR to any of the first line drugs was $9.8 \%$ and multi drug resistance $(\mathrm{RMP}+1 \mathrm{NH})$ in untreated patients was $8.6 \%$.

Table No. I

Resistance pattern of all the isolates

\begin{tabular}{|c|c|c|c|c|c|c|}
\hline \multirow{3}{*}{$\begin{array}{l}\text { S. } \\
\text { No. }\end{array}$} & \multirow{3}{*}{$\begin{array}{l}\text { Drug Susceptibility } \\
\text { testing results }\end{array}$} & \multicolumn{4}{|c|}{$\begin{array}{l}\text { No. of culture positive patients tested } \\
\text { for drug susceptibility }\end{array}$} & \multirow[t]{3}{*}{ Total } \\
\hline & & \multicolumn{2}{|c|}{ Untreated } & \multicolumn{2}{|c|}{ Treated } & \\
\hline & & No & $\%$ & No & $\%$ & \\
\hline 1 & Total tested & 70 & & 4 & & 74 \\
\hline 2 & Sensitive & 63 & 90.0 & 0 & 0 & 63 \\
\hline 3 & $\begin{array}{l}\text { Resistance to } 1 \text { drug } \\
\text { EMB }\end{array}$ & 1 & 1.4 & & & 1 \\
\hline 4 & $\begin{array}{l}\text { Resistance to } 2 \text { drugs } \\
\text { RMP+INH }\end{array}$ & 3 & 4.3 & 1 & 25.0 & 4 \\
\hline 5 & $\begin{array}{l}\text { Resistance to } 3 \text { drugs } \\
\text { RMP+INH+EMB }\end{array}$ & 2 & 2.8 & 2 & 50.0 & 4 \\
\hline 6 & $\begin{array}{l}\text { Resistance to } 4 \text { drugs } \\
\text { RMP+INH+SM+EMB }\end{array}$ & 1 & 1.4 & 1 & 25.0 & 2 \\
\hline 7 & $\begin{array}{l}\text { Multi drug resistance } \\
\text { RMP+INH }\end{array}$ & 6 & 8.6 & 4 & 100 & \\
\hline
\end{tabular}

\section{DISCUSSION}

The objectives of this study were to ascertain the level of antimicrobial resistance in patients diagnosed at hospital. The study revealed that the $90 \%$ of isolates were sensitive to all four drugs and $10 \%$ of the isolates had primary resistance to one or more drugs tested against it and $8.6 \%$ of the isolates were multidrug resistances (MDR). Of the 
74 isolates four strains were isolated from previously treated cases and all isolates were multi drug resistant. It is very rare to have past history of treatment and only 4 (5.4\%) patients had given past history of treatment with anti-tubercular drugs. Similar study in German Nepal tuberculosis project demonstrated that the level of MDR resistance in untreated cases was $5.7 \%$ and $1.6 \%$ in $1987-1990$ and 1991-1994, respectively. The study also showed that the level of MDR was $30 \%$ of the isolates in 1987-1990 and around 10\% in 1990-1994 study period. ${ }^{10}$ In comparison to these studies, the WHO/ IUALTD global project on anti-tuberculosis drug resistance surveillance conducted in 1994-1997 showed monoreresistance in $5.7 \%$ and multidrug resistance in $1.1 \% .^{5}$ And the recent antituberculosis drug resistance by WHO/IUALTD showed that mono resistance was in $4.8 \%$ and Multidrug resistance in $1 \%$ of new cases and monoresistance in $7.4 \%$ and multidrug resistance in $7.4 \%$ among previously treated cases. ${ }^{11}$

\section{CONCLUSIONS}

The present study showed relatively high level of monoresistance and also MDR in new cases. Almost all other studies and present study in Nepal reveled high level of MDR in previously treated cases. The study shows that the burden of MDRTB is high in the community. Poor case management may have led to acquired resistance in patients who then infected their contacts with primary resistant strains of tuberculosis. This study shows an urgent need to establish effective TB control activities.

\section{ACKNOWLEDGEMENT}

We thank MS Nina Mattock, Tropical Disease Research, WHO, Geneva, Switzerland for review of our manuscript and also for her valuable suggestions.

\section{REFERENCES}

1. Rook G.A.W, Seah G., Ustianowski A. M.tuberculosis:Immunology and vaccination. Eur.Respir J .2001;17:537-557.

2. SAARC Tuberculosis Center. The role of SAARC TB Center in Tuberculosis Control. Released on world TB day 2001by SAARC Tuberculosis Center, Kathmandu,Nepal:1-2.

3. Rijal B, Banajede NR, J oshi HH,Pokhrel BM and Tuladhar NR. The incidence of tuberculosis in suspected tuberculosis patients. Souvenir, Second Congress of Association of Clinical Pathologists of Nepal1997;2(2):49.

4. Rijal B,Tuladhar NR, Khagi AR,Banajede NR, Bam DS, Sharma AP.Age and sex distribution in Tuberculosis. J ournal of the Nepal Associationfor Medical laboratory Sciences 2000;2(2):69-71.

5. World Health Organization and International Union against Tuberculosis and Lung Diseases. Antituberculosis Drug Resistance in the World, WHO/ IUALTD Global Project on Anti-Tuberculosis Drug ResistanceSurveillance1994-1997. WHO document WHO/TB/97.229.

6. Thakker $\mathrm{H}$ and Shah J.R. Multi drug resistant pulmonary Tuberculosis Review article Ind J TB 1998; 45: 131-139.

7. Schwoebel V, Weezenbeek CBSL, Moro ML, Drobniewski F, Hoffner SE, Raviglione MC and Rieder HI.Standadrzation of Antituberculosis drug resistance surveillance in Europe.Eur Respir J 2000; 16:364-371

8. Malla P. Factors associated with treatment failures in tuberculosis patients at national tuberculosis center. J ournal of the Nepal Medical association. T.B special 1996; vol 34. 117: 41-46.

9. Helbling P,Altpeter,RaeberP-A, PfyfferG.E, Zellweger J-P. Surveillance of Antituberculosis drug resistance in Switzerland 1995-1997: the central link. Eur Respir J 2000; 16:200-202

10. Shrestha B, Neher A,Breyer O, Feldmann K. The pattern of antitubercular drug resistance in patients treated at an urban tuberculosis clinic in Katmandu velly. Journal of the Nepal Medical association. T.B special 1996; 34.(117)36-40.

11. World Health Organization and International Union Against Tuberculosis and Lung Diseases. Antituberculosis Drug Resistance in the World, Report No 2, Prevalence and TrendsThe WHO/IUALTD Global Project on Anti-Tuberculosis Drug ResistnnceSurveillance1994-1997. WHO document WHO/CDS/TB/2000.278 